Development of a Novel Depleted Uranium Treatment Process at Lawrence Livermore National Laboratory

D. Gates-Anderson, J. Bowers, C. Laue, T. Fitch

February 13,2007

American Society of Civil Engineers Practice Periodical of Hazardous, Toxic, and Radioactive Waste Management 
This document was prepared as an account of work sponsored by an agency of the United States government. Neither the United States government nor Lawrence Livermore National Security, LLC, nor any of their employees makes any warranty, expressed or implied, or assumes any legal liability or responsibility for the accuracy, completeness, or usefulness of any information, apparatus, product, or process disclosed, or represents that its use would not infringe privately owned rights. Reference herein to any specific commercial product, process, or service by trade name, trademark, manufacturer, or otherwise does not necessarily constitute or imply its endorsement, recommendation, or favoring by the United States government or Lawrence Livermore National Security, LLC. The views and opinions of authors expressed herein do not necessarily state or reflect those of the United States government or Lawrence Livermore National Security, LLC, and shall not be used for advertising or product endorsement purposes. 


\title{
Development of a Novel Depleted Uranium Treatment Process \\ at Lawrence Livermore National Laboratory
}

\author{
Dianne Gates-Anderson ${ }^{1}$, John Bowers ${ }^{2}$, Carola Laue ${ }^{3}$, and Thomas Fitch ${ }^{4}$
}

\begin{abstract}
A three-stage process was developed at Lawrence Livermore National Laboratory to treat potentially pyrophoric depleted uranium metal wastes. The three-stage process includes waste sorting/rinsing, acid dissolution of the waste metal with a hydrochloric and phosphoric acid solution, and solidification of the neutralized residuals from the second stage with clay. The final product is a solid waste form that can be transported to and disposed of at a permitted low-level radioactive waste disposal site.
\end{abstract}

CE Database Subject Headings: Radioactive Wastes, Uranium, Waste Management

\footnotetext{
${ }^{1}$ Environmental Process Engineer, Lawrence Livermore National Laboratory, 7000 East Ave, Livermore, CA 94550. E-mail: gatesdd@1lnl.gov

${ }^{2}$ Group Leader, Process Engineer, Lawrence Livermore National Laboratory, 7000 East Ave, Livermore, CA 94550. Email: bowers3@1lnl.gov

${ }^{3}$ Environmental Radiochemist Post-Doc, Formerly Lawrence Livermore National Laboratory. Email: calaue@comcast.net

${ }^{4}$ Chemist, Lawrence Livermore National Laboratory, Lawrence Livermore National Laboratory, 7000 East Ave, Livermore, CA 94550. Email: fitch3@1lnl.gov
} 


\section{INTRODUCTION}

Uranium is a silvery metallic element that is found in the earth's crust in trace quantities. In nature, several isotopes of uranium are found, with the abundance of the naturally occurring isotopes ${ }^{234} \mathrm{U},{ }^{235} \mathrm{U},{ }^{238} \mathrm{U}$ being $0.005,0.72$ and $99.275 \%$ respectively. When the abundance of ${ }^{235} \mathrm{U}$ in a specimen is less than $0.7 \%$ it is considered "depleted". Depleted uranium (DU) is a byproduct of the enrichment processes used to generate fissionable materials for weapons and energy production. Three hazards are associated with uranium and depleted uranium metal; pyrophoricity, toxicity and radioactivity.

Of DU metal's three hazardous characteristics, its pyrophoricity is the one that provides the greatest impediment to disposal in the USA. Uranium metal is a highly reactive because its valence electron structure, $[\mathrm{Rn}] 5 \mathrm{f}^{3} 6 \mathrm{~d}^{1} 7 \mathrm{~s}^{2}$ make the metal easy to oxidize. In fact, finely divided uranium metal powders may ignite spontaneously. Because of the hazards associated with depleted uranium, the storage, treatment, transport, and disposal of uranium wastes are strictly regulated by the Nuclear Regulatory Commission, the Department of Energy, and the Department of Transportation to ensure that human health and environmental integrity are protected. In addition, the Environmental Protection Agency regulates the disposition of mixed waste depleted uranium, because of the hazardous constituents. A few disposal sites such as the Nevada Test Site will accept low level DU waste. It is much more challenging to find a land disposal site that will accept mixed DU waste. 
Lawrence Livermore National Laboratory (LLNL) had an inventory of at least 11,700 $\mathrm{kg}$ (33 $\mathrm{m}^{3}$ ) of pyrophoric DU metal waste that required treatment to render it suitable for disposal. Waste DU metal can be found in many physical forms including chips, turnings, chunks, sludges, and large fragments and may be pure elemental uranium or an alloy of uranium with other metals such as niobium, molybdenum, iron, or titanium. Most of the DU waste at LLNL was generated during the machining of components from bulk DU and uranium alloy metals. Typically uranium wastes were collected from troughs beneath the machining equipment or placed directly into steel drums. A significant portion of the LLNL DU waste stream is classified as mixed waste (low level radioactive plus RCRA hazardous). Fluids used during the machining of uranium including some coolants, lubricants, and chlorinated solvents used to polish and degrease metal parts often introduced hazardous compounds into this waste stream resulting in the generation of a mixed waste. In addition, the equipment used to machine DU was also used to machine other metals and in many instances the scrap waste materials from the equipment were commingled. At LLNL the toxic metals most frequently combined with DU waste include lead, cadmium, and beryllium.

In order to remain in compliance with Federal Facility Compliance Act agreements made between LLNL and the California Environmental Protection Agency, LLNL is obligated to manage its inventory of stored mixed waste depleted uranium. Because waste management personnel at LLNL did not have a viable disposal pathway for mixed waste depleted uranium waste, we decided to develop a process to treat this waste onsite and make the waste suitable for offsite disposal at a permitted low level radioactive land disposal facility. The outcome of this effort is a 3-stage process that converts pyrophoric depleted uranium metal turnings into 
a solidified final product that can be transported to and buried at a permitted low level waste land disposal site. The three process stages are:

1) Pretreatment, which includes sorting and washing of DU waste,

2) Dissolution of DU waste in an acid solution to convert the U to a non-pryophoric form, and

3) Solidification of the dissolution byproducts to form a solid monolith that is suitable for off-site land disposal.

Uranium is a very reactive element and its metallurgical treatment and composition have a pronounced effect on its corrosion and dissolution behavior. The dissolution behavior of metallic uranium is comparable to that of magnesium. Larsen, 1959; Katz and Rabinowitch, 1951; and Roden, 1950, all present extensive reviews of uranium dissolution. There are few documented accounts of the use of acidic dissolution reactions as a means to treat depleted uranium waste. Czupryna et al., 1987 evaluated several reagent systems for the dissolution of $0.75 \%$ titanium/depleted uranium alloys that were contaminating stainless steel armor targets. Many of the reagent systems that they expected to work were ineffective for reasons that they could not explain. Czupryna et al., 1987 concluded that $4 \mathrm{~mol} / \mathrm{L} \mathrm{HCl}: 7 \mathrm{~mol} / \mathrm{L}$ $\mathrm{H}_{3} \mathrm{PO}_{4}$ was the most effective and practical reagent for the treatment of targets contaminated with $0.75 \% \mathrm{Ti} / \mathrm{U}$ alloys. 


\section{LLNL DU Process Development}

Although uranium dissolution is discussed extensively in the literature, information that is pertinent to the use of chemical dissolution as a treatment process is lacking. Processes used for the dissolution of fuel assemblies tend to be very aggressive and require highly specialized and costly capital equipment. Analytical procedures use small amounts of metals and reagents and less attention is paid to the corrosiveness of the reagents and other hazards associated with the dissolution reactions than would be required for a full-scale treatment process. Parameters vital to scaling up a dissolution processes for waste treatment purposes, such as rate of reaction, heat of reaction, off-gas generation, and disposal characteristics of residuals formed are often not considered when developing analytical dissolution processes. In addition, the behavior and fate of hazardous constituents such as volatile organic compounds and toxic metals during and following DU treatment needs to be understood and may influence the selection of the most appropriate dissolution system.

In order to address these information gaps, we initiated a series of laboratory studies to develop a comprehensive DU treatment process. Our desire was to develop and design a treatment process that could treat up to $80 \mathrm{~kg}$ of DU a day. A dissolution process was desired because we wanted complete conversion (destruction) of the metallic DU waste form instead of non-destructive encapsulation of the waste, which may not be viewed favorably by all regulators, or thermal processing of the waste that would be extremely difficult to obtain an operating permit for. 
We began our work with a screening study designed to evaluate many of the acid systems reported in the literature, in order to determine which systems might be applicable to depleted uranium waste while minimizing the amount of waste generated. Reagent systems that were screened included sulfuric, phosphoric, nitric, and hydrochloric acid, hydrogen peroxide, sodium hypochlorite, and sodium hydroxide used either individually or in combination (Table 1). These systems were selected for study after an extensive literature review was completed (Laue et al., 2004a). We evaluated the dissolution systems in series, beginning with the least aggressive system. The methods and materials selected for the screening study were selected to ensure reproducible results and minimize the amount of waste generated during experimentation.

Depleted uranium turnings were obtained from the Manufacturing and Materials Engineering Division of LLNL. The dry-stored turnings were of known compositions and size. The turnings were 4 mil thick $(0.1 \mathrm{~mm})$. Two different depleted uranium metals were utilized in our investigations; pure depleted uranium (DU) and a uranium-molybdenum alloy that contains $2 \%$ molybdenum by weight $(2 \% \mathrm{Mo})$. All chemicals used were of ACS reagent grade quality. Acid solutions were prepared by mixing and/or diluting the concentrated acids (sulfuric $18 \mathrm{~mol} / \mathrm{L}$, hydrochloric $12 \mathrm{~mol} / \mathrm{L}$, phosphoric $15 \mathrm{~mol} / \mathrm{L}$, and nitric $15 \mathrm{~mol} / \mathrm{L}$ ) with double distilled water. Hydrogen peroxide (30\%) and sodium hypochlorite $(6 \%)$ were obtained shortly prior to our experiments and used as delivered. The sodium hydroxide solution $(1 \mathrm{~mol} / \mathrm{L})$ was prepared as needed, by dissolving the appropriate amount of $\mathrm{NaOH}$ pellets. Individual reactions were performed in disposable $50 \mathrm{~mL}$ plastic vials or $65 \mathrm{~mL}$ glass test tubes. All reagent solutions were evaluated using 1-g of DU or $2 \% \mathrm{Mo}$. The uranium was 
always added to the reagent mixture in the reaction vessel. A vortex mixer was utilized when the reaction needed agitation. Reactions requiring elevated temperatures were performed in a heating block suitable for the test tubes. Reagent solutions were heated to the desired temperature prior to the addition of uranium turnings. The time to complete the dissolution and the characteristics of the reaction product observed were noted. In some cases, the increase in temperature was recorded.

Several of the systems evaluated in the screening study were able to completely dissolve the DU and DU alloy (Table 2). Our next task was to select from the several effective dissolution systems the one that would be most feasible for an onsite treatment process. The following criteria were established as being essential for a waste DU dissolution system:

- Operating conditions: The reagent system selected must proceed at an acceptable dissolution rate at ambient temperature and pressure. It was our desire to avoid the energy costs and potential hazards associated with heating treatment reagents, prior to DU treatment.

- Treatment time: The reagent system selected must be capable of completely dissolving uranium in a reasonable time period. The dissolution time must be less than 6 hours to allow a batch of waste to be dissolved during 1 workday.

- Applicability: The reagent system selected must meet the above 2 criteria for both pure uranium metals and uranium alloys. The reagent system must also be applicable to turnings, sludges and chips. 
The dissolution systems that met the essential treatment criteria listed above were then further compared using the following criteria, listed in descending order of significance, to facilitate the selection of the system most suitable for full-scale implementation at LLNL:

- Hazardous by-products: The generation of hazardous reaction products that would compromise worker safety or require further treatment must be avoided.

- Temperature increase: All dissolution reactions evaluated were exothermic. It was our desire to select an effective dissolution system that had acceptable reaction rates with the least increase in temperature.

- Off-gas: Many of the dissolutions systems evaluated generated an off-gas during dissolution. Processes with no or minimal off-gases were preferred over those that generated a larger volume of off-gas.

- Corrosiveness: The least aggressive reagent solution that met the essential criteria was desired in order to minimize worker hazard and equipment cost. Some of the more aggressive reagent systems may require equipment constructed of costly materials.

- Complexity: The least complex dissolution system with the fewest required treatment steps was desired.

- Final waste volume: Because offsite disposal costs are based on the volume of waste, reagent systems that generated lower volumes of residuals were preferred over those that generated larger volumes.

Following the initial screening experiments, phosphoric plus hydrochloric acid treatment was determined to be the most suitable reagent system and selected for further study (Laue et al., 
2004b). $\mathrm{HCl} / \mathrm{H}_{3} \mathrm{PO}_{4}$ is able to fully dissolve DU and DU alloy at ambient temperature without the formation of pryophoric by-products or the generation of large quantities of hazardous off-gases. A follow-on series of experiments was completed with $\mathrm{HCl} / \mathrm{H}_{3} \mathrm{PO}_{4}$. The objective of this series of experiments was to:

- Determine the optimum $\mathrm{HCl}$ and $\mathrm{H}_{3} \mathrm{PO}_{4}$ acid concentration for safe dissolution of uranium and uranium alloys

- Determine the quantity and composition of secondary waste generated

- Evaluate reaction kinetics and thermodynamics

Turnings of pure depleted uranium and the uranium alloy U-2\%Mo collected in three different sizes; 4, 8 and 16 mil were used for this series of experiments. Initially, 1 gram of DU and 2\%Mo-U alloy turnings were treated with $25 \mathrm{~mL}$ of a $7 \mathrm{~mol} / \mathrm{L} \mathrm{H}_{3} \mathrm{PO}_{4} / 4 \mathrm{~mol} / \mathrm{L} \mathrm{HCl}$ solution at $85^{\circ} \mathrm{C}$. For subsequent studies the acid concentration, liquid to solid ratio, and temperature were varied. We observed that the reaction of the $\mathrm{HCl} / \mathrm{H}_{3} \mathrm{PO}_{4}$ acid mixture with the uranium metal changed from complete dissolution to complete conversion as the acid concentrations were decreased. The conversion results in the direct formation of the hygroscopic sludge-like solid. No metallic residues were observed. The change from complete dissolution to complete metal conversion occurs if the phosphoric acid concentration was equal to or below $4 \mathrm{~mol} / \mathrm{L}$ or if the hydrochloric acid concentration was below $2 \mathrm{~mol} / \mathrm{L}$.

The solids formed are greenish-gray in color, suggesting the formation of a solid containing uranium in its tetravalent oxidation state. Several analytical methods including X-ray absorption fine structure spectroscopy (XFAS), X-ray fluorescence spectroscopy (XRF) and 
scanning electron microscopy (SEM) were used to characterize the solids formed. Our desire was to determine if the solids were the same as those reported in the literature and to determine if the solids contained any chlorine. The latter information is needed to facilitate the selection of suitable materials of construction for interim and final disposal containers. Examining the solids under a scanning electron microscope revealed a fibrous structure (Figure 1), which explains the solid's extreme hygroscopic nature resulting in the ability to absorb large quantities of free liquids. Based on our XFAS analysis, we determined that the solids formed did not contain any chlorine and were comprised solely of $\mathrm{U}, \mathrm{P}, \mathrm{O}$ and $\mathrm{H}$. This finding is in agreement with the work of Schreyer, 1955 that report the formation of uranium hydrogen phosphate compounds at ambient temperature from $\mathrm{U}^{4+}, \mathrm{Cl}$, and phosphoric acid systems. Similar findings were also reported by Brandel and Dacheux, 2004.

We hypothesize that the hydrochloric acid in the reagent mixture catalytically oxidizes the uranium metal to $\mathrm{U}^{4+}$. Phosphoric acid is a strong uranium ion complexing agent and the uranium-IV-ions formed are immediately complexed by the phosphate ions, making the conversion from metal into the phosphate solid nearly instantaneous. This immediate complexation prevents the formation of the finely divided black $\mathrm{UO}_{2}$ precipitate usually observed during the dissolution of uranium in solutions with hydrochloric acid only (Katz and Rabinowitch, 1951). The conversion of the metal to the phosphate solid (eq. 1 and 2) results in an irreversible removal of the uranium and hydrogen phosphate ions from the reagent mixture.

$$
\mathrm{U}+4 \mathrm{H}_{3} \mathrm{O}^{+} \rightarrow \mathrm{U}^{4+}+4 \mathrm{H}_{2} \mathrm{O}+2 \mathrm{H}_{2}
$$




$$
\mathrm{U}^{4+}+\mathrm{x} \mathrm{H}_{2} \mathrm{PO}_{4}^{-} \rightarrow\left[\mathrm{U}^{-}\left(\mathrm{H}_{2} \mathrm{PO}_{4}\right)_{\mathrm{x}}\right]^{(4-\mathrm{x})^{+}}
$$

\section{PROCESS SCALE-UP}

After the laboratory studies were completed, the decision was made to design and build a full-scale DU treatment unit at LLNL. The remainder of this paper will discuss the fabrication of this unit, which to date has been used for the completion of a $5 \mathrm{~kg}$ treatment trial. The Decontamination and Waste Treatment Facility (DWTF) where DU treatment will be conducted, was designed and permitted for the processing of low level, hazardous and mixed waste. It includes a $481 \mathrm{~m}^{3}\left(17,000 \mathrm{ft}^{3}\right)$ solid and liquid waste processing area with a state of the art process off gas treatment system and other design features to address routine hazards associated with the types of waste treated in the facility. We wanted to build a transportable unit similar to a uranium treatment unit described by Lussiez and Zygmunt, 1993, in order to maximize the use of available space in DWTF. Our primary consideration when scaling the treatment process from lab-scale to full-scale was operator safety. Hazards, specific to the DU treatment process that needed to be addressed during process scale-up and design included:

- Ignition of untreated DU waste

- Corrosivity of treatment reagents 
- Hydrogen gas generated during dissolution and neutralization reactions

- Heat generated during exothermic dissolution and neutralization reactions

Full-scale treatment of DU will take place in the DWTF high bay area and reactives treatment cell and includes 3 processing stages: 1) waste draining, sorting and washing, 2) DU dissolution, and 3) solidification of dissolution residuals. A schematic of the full-scale process is given in Figure 2. The treatment unit is designed to operate in batch mode and treat up to $80 \mathrm{~kg}$ of DU waste a day. The design capacity of $80 \mathrm{~kg}$ per day was selected in order to remain in compliance with the DWTF RCRA operating permit. The equipment used includes 1) stainless steel waste sorting table for stage 1 sorting and washing, 2) Hastelloy-C reaction vessel for second stage uranium deactivation, and 3) double planetary mixer for stage three solidification.

The equipment is considered portable and can be moved in and out of the treatment areas using a forklift. Electric power, process water, and air supplies are from the building utility system. The skid anchoring and other structural supports of the process equipment were designed to meet $\mathrm{CA}$ seismic requirements. The uranium dissolution skid also includes reagent feed pumps to transfer the acids (phosphoric and hydrochloric acids) and sodium hydroxide from their respective containers, water delivery from a hose bib or pumping system, and a crane to facilitate waste loading into the reaction vessel. The remainder of this paper will discuss the operation of the full-scale treatment unit. 
Stage I: Draining, sorting and washing

Waste depleted uranium is typically stored in 114 and 208 liter (30 and 55 gal) drums immersed in a storage solution such as coolant, mineral oil or water in order to minimize contact with air. Most of the DU storage solutions have a high concentration of organic compounds that are incompatible with the acids selected for dissolution. Also, in mixed waste depleted uranium, some hazardous constituents may be dissolved in the storage solution. Therefore, pretreatment is required to remove all traces of storage solution from the DU solids. An additional goal of pretreatment is to obtain a defined and reproducible starting condition for the subsequent acid dissolution treatment process. Pretreatment includes separating the turnings from the storage solution, removing non-metal items from the waste and washing the turnings to remove traces of storage solution from the depleted uranium solids.

Containers are processed individually in stage I. First, the drum lid is replaced with a modified metal lid that has a pouring spout and a mesh splashguard. During DU treatment, the greatest ignition hazard exists when the waste containers are first opened, prior to draining and sorting. Hydrogen gas has been know to accumulate in containers of DU waste as a result of chemical oxidation reactions occurring during storage and explosions have occurred during lid removal when the accumulated $\mathrm{H}_{2}$ gas is ignited (Solbrig, 1994). In order to minimize this hazard, drums of DU waste will be grounded before opening and nonsparking tools will be used when removing the lid. In addition, a gas meter will be inserted in the waste container headspace prior to full removal of the lid. If hydrogen gas is detected 
in the headspace, the container will be allowed to vent until the $\mathrm{H}_{2}$ concentration is below the LEL, prior to lid removal. The gas meter used will also indicate if an explosive environment is present at anytime during the venting process. No ignition sources are present during container opening and venting, in the event that an explosive environment is encountered before complete venting of the container headspace is accomplished. A fork truck with an articulating drum lifter attachment is then used to lift the drum and rotate it over a custom fabricated sorting table. The sorting table was fabricated with stainless steel and will be used to both sort and wash the uranium to prepare it for delivery to the reaction vessel. The sorting table is elevated to allow the placement of 114 or 208 liter (30 or 55 gal) drums under the table to collect the washed and sorted uranium and spent wash solutions. The sorting table has two openings. One opening is covered with $0.64 \mathrm{~cm}(1 / 4 \mathrm{inch})$ stainless steel mesh and is used to drain liquids from the table to one of the drums positioned beneath the table. While draining, sorting and washing of the waste occurs, the second (unscreened) hole is covered by stainless steel sliding plate. Clearly non-uranium bearing wastes such as lab trash, and personal protective equipment is removed and placed in a separate waste containers. Large chunks and fragments of DU are also removed during this stage. After the waste has been sorted, it is washed and rinsed as needed. The rinse water and storage solutions are consolidated when appropriate and stored onsite, prior to treatment in the DWTF liquid waste processing unit. Once the uranium is rinsed and all excess liquids have drained into the drum below, the sliding plate is repositioned and the uranium metal is transferred using hand tools into separate drums via the unscreened opening in the sorting table. Individual drums are filled with $80 \mathrm{~kg}$ of DU, the maximum amount of DU that can be treated at one time in the dissolution reactor. 
Stage II: Dissolution and neutralization

A 1200 liter Hastalloy C reactor is used for DU dissolution and neutralization. Hastalloy C, a nickel-chromium-molybdenum alloy, was selected as the material of construction due to its exceptional resistance to mineral acids and chlorine at both ambient and elevated temperatures. The reactor is essentially a $1.6 \mathrm{~m}$ diameter steam kettle with a cooling jacket that allows the use of house low conductivity-water to cool the reactor contents as the reaction progresses. The dimpled jacket has two inlet nozzles and one outlet nozzle for the circulation of cooling media. This reactor is secured to a skid-mounted platform with forklift pockets to allow the system to be easily transported. The reactor was purchased from a commercial vendor and was sized to allow sufficient head space to prevent splashed reagents from leaving the reactor, provide room for product expansion and provide enough heat exchange surface to facilitate heat removal when needed.

Reagents will be supplied in 870 liter ( $230 \mathrm{gal})$ transportable containers and stored outdoors when not in use. The double-walled portable tanks are fabricated of high-density polyethylene, with steel forklift pockets attached to the bottom and include a tapered secondary containment cylinder capable of containing the entire volume if primary container were to leak. At the top of the tank lid there is a threaded cap that is used for filling and removing reagent from the tank. The acid tanks are moved from the outdoor storage area to the DU treatment room on an as needed basis using a forktruck. For each $80 \mathrm{~kg}$ batch, 587 liters (155 gal) of stock (15\%) HCl solution and 102 liters (27 gal) of stock $(75 \%) \mathrm{H}_{3} \mathrm{PO}_{4}$ will 
be added to the reaction vessel. In order to dilute the acids to the desired treatment concentration 114 liters ( $30 \mathrm{gal})$ of water is mixed with the acids.

Once the acid solution has been prepared in the reaction vessel, the washed uranium is added using a manually operated davit crane. The hand-crank jib crane is mounted on the reactor skid, and platform steps are located next to the reactor skid to facilitate the ergonomic introduction of uranium solids into the reactor. The temperature of the reaction vessel is continuously monitored and uranium is added only if the temperature is sufficiently low or is stabilized. During and immediately following uranium addition, large polyethylene paddles are used to mix the contents of the reactor to ensure that all of the introduced solids are contacted by the acid solution. After all of the DU for a batch has been added to the reactor, the dissolution reaction is allowed to proceed for up to 4 hours. During this reaction period no mixing is required. The temperature within the reactor is monitored and cooling water can be circulated if temperature approaches predetermined limits.

When the dissolution process is completed, the wet amorphous solids in the reactor are neutralized with sodium hydroxide $(\mathrm{NaOH})$ solution. Our desire is to increase the $\mathrm{pH}$ of the reactor contents from zero to between 2 and 3 . Sodium hydroxide ( $50 \%$ by wt solution) is obtained from a permanently installed DWTF reagent storage tank. It will take about 189 liters (50 gal) of $50 \%$ sodium hydroxide to neutralize a full $80 \mathrm{~kg}$ of DU batch.

Following neutralization, the contents of the treatment reactor are transferred to suitable holding containers to await solidification. A wet-dry vacuum was used as the primary 
removal method during smaller scale $(5 \mathrm{~kg})$ treatment trials. For $80 \mathrm{~kg}$ batches a combination of pumping out the tank via the bottom nozzle and wet-dry vacuuming will be used. The slurry may be place directly in plastic lined (90 mil thickness) 208liter (55-gal) drums or consolidated into larger, portable poly-tanks.

The neutralized slurry will be solidified in 208 liter drums using a double planetary mixer. Waste solidification is a routine, RCRA-permitted waste treatment operation at LLNL and no modifications were required for the DU waste treatment process. The solidification agent is a clay-based material that has been demonstrated in the laboratory to retain any RCRA metals that may be commingled with the DU waste. The final waste form generated by the solidification stage is a solid monolith in 208 liter drums that can be land disposed of as a low level radioactive waste.

\section{CONCLUSIONS}

Researchers at LLNL have successfully developed and are ready to deploy a novel DU metal treatment process. To date, a $5 \mathrm{~kg}$ trial has been completed and all equipment, supplies, and procedures are in place for the full-scale implementation of this process. We continue to seek improvements to the process that will decrease the volume of waste to be landfilled. The cost of this process was examined in a semi quantitative sense and was compared with other accepted LLW and mixed waste treatment processes. It was determined that the cost of this process is high for low-level waste not needing to meet RCRA land disposal restrictions, 
but was reasonable for mixed wastes needing rigorous treatment to remove hazardous characteristics in addition to the pyrophoricity of the DU. The cost of processing and disposal of the residue for mixed waste is less than the cost that would be incurred if the waste were to remain in storage at LLNL for any period of time greater than 3 years. 


\section{ACKNOWLEDGEMENTS}

Nora Briant, Steve Steward provided considerable assistance during this project. The authors would also like to acknowledge the contribution of the RHWM waste treatment technicians including Chris Rasmussen, Gary Striker, Steve Ebisuzaki, and Chris Green.

This work was performed under the auspices of the U.S. Department of Energy by the University of California, Lawrence Livermore National Laboratory under Contract NumberW-7405-Eng-48. UCRL-JRNL-227969

\section{REFERENCES}

Brandel, V., and Dacheux, N. (2004) "Chemistry of Tetravalent Actinide Phosphates, Part I." J. Sol State Chem, 177, 4743.

Czupryna, G., Levy, R.D., and Gold, H. (1987) "Selective Dissolution and Recovery of Depleted Uranium From Amor Plate.” Foster-Miller, Inc. Final Report \#MER-0017-FMI8644-80, Waltham, MA.

Katz, J.J., and Rabinowitch, E. (1951) Chemistry of Uranium, McGraw-Hill Book Co., New York.

Larsen, R.P. (1959) “Dissolution of Uranium Metal and Its Alloys.” Anal Chem. 31, 545549. 
Laue, C.A., Gates-Anderson, D.D., and Fitch, T.E. (2004a) "Dissolution of Metallic Uranium and It's Alloys Part I: Review Of Analytical And Process-Scale Metallic Uranium Dissolution.” J Rad Nuc Chem. 261, 709-717.

Laue, C.A., Gates-Anderson, D.D., and Fitch, T.E. (2004b) “Dissolution of Metallic Uranium and It's Alloys Part II: Screening Study Results: Identification of an Effective Non-Thermal Uranium Dissolution Method." J Rad Nuc Chem. 262,517-524.

Lussiez, G., and Zygmunt, S. (1993) "The Hazardous Waste Treatment Facility and Skidmounted Treatment System at Los Alamos.” LANL report \# LA-UR-93-1205, Las Alamos, NM.

Roden, C.J. (1950) Analytical Chemistry of the Manhattan Project, McGraw-Hill Book Co., New York.

Schreyer, J.M. (1955) "The Solubility of Uranium(IV) Orthophosphates in Phosphoric Acid Solutions.” J. Am. Chem. Soc. 77, 2972.

Solbrig, C.W. (1994) "Pyrophoricity of Uranium in Long-Term Storage Environments." Argonne National Laboratory Report \# ANL/TD/CP—84441, Chicago, IL. 
Table 1. List of reagent systems and treatment conditions evaluated in screening study.

\begin{tabular}{|c|c|c|c|}
\hline Reagent system & Concentration & Temperature ( C) & $\begin{array}{l}\text { Volume reagent per } 1 \mathrm{~g} \\
\text { Dep-U (mL) }\end{array}$ \\
\hline Sodium hypochlorite & 1.0 & $25,40,50$ and 60 & $5,10,15,20$ and 25 \\
\hline $\begin{array}{l}\text { Sodium hypochlorite } \\
\text { Hydrogen peroxide }\end{array}$ & $\begin{array}{l}1.0 \\
10.0\end{array}$ & 25 & $\begin{array}{l}25 \mathrm{ml} \mathrm{NaOCl} \\
10 \mathrm{ml} \mathrm{H} \mathrm{O}_{2}\end{array}$ \\
\hline $\begin{array}{l}\text { Sulfuric acid } \\
\text { Hydrochloric acid } \\
\text { Hydrogen peroxide }\end{array}$ & $\begin{array}{l}7 \mathrm{M} \\
0.1 \text { to } 1 \mathrm{M} \\
0.1 \text { to } 1 \mathrm{M}\end{array}$ & $25,35,45,65$ & 9 \\
\hline $\begin{array}{l}\text { Sulfuric acid } \\
\text { Nitric acid }\end{array}$ & $\begin{array}{l}3,7.5,12 \mathrm{M} \\
0.1,1,2 \mathrm{M} \\
\end{array}$ & $25,40,5,70$ & $10,25,30,40$ \\
\hline $\begin{array}{l}\text { Hydrochloric acid }(3 \mathrm{M}) \\
\text { Ferric chloride }(0.2 \mathrm{M})\end{array}$ & $\begin{array}{l}3 \mathrm{M} \\
0.2 \mathrm{M}\end{array}$ & 25 & 50 \\
\hline $\begin{array}{l}\text { Hydrochloric acid } \\
\text { Ferric sulfate } \\
\text { Hydrogen peroxide }\end{array}$ & $\begin{array}{l}3 \mathrm{M} \\
0.2 \mathrm{M} \\
30 \% \\
\end{array}$ & 25 & $\begin{array}{l}50 \mathrm{ml} \mathrm{HCl} / \mathrm{Fe}\left(\mathrm{SO}_{4}\right)_{3} \text { plus } \\
\text { repeated } 1 \mathrm{~mL} \text { additions } \\
\text { of } \mathrm{H}_{2} \mathrm{O}_{2}\end{array}$ \\
\hline $\begin{array}{l}\text { Phosphoric acid } \\
\text { Hydrochloric acid }\end{array}$ & $\begin{array}{l}1,2,3,6,7 \mathrm{M} \\
1,2,3,4 \mathrm{M}\end{array}$ & $25,35,45,55,65$ & $5,10,15,20$ and 25 \\
\hline $\begin{array}{l}\text { Sodium hydroxide } \\
\text { Hydrogen peroxide }\end{array}$ & $\begin{array}{l}1 \mathrm{M} \\
5 \mathrm{M} \\
\end{array}$ & $25,40,65$ & 25,50 \\
\hline Nitric acid & $1,8,12$, and $15 \mathrm{M}$ & $25,40,60$ & $25(?)$ \\
\hline $\begin{array}{l}\text { Nitric acid } \\
\text { Sulfuric acid }\end{array}$ & $\begin{array}{l}12 \mathrm{M} \\
0.3,0.6,2 \mathrm{M}\end{array}$ & 40 & 25 \\
\hline $\begin{array}{l}\text { Nitric acid } \\
\text { Phosphoric acid }\end{array}$ & $\begin{array}{l}12 \mathrm{M} \\
0.3,0.6,2 \mathrm{M}\end{array}$ & 40 & 25 \\
\hline $\begin{array}{l}\text { Nitric acid } \\
\text { Hydrochloric acid }\end{array}$ & $\begin{array}{l}12 \mathrm{M} \\
0.3,0.6,2 \mathrm{M}\end{array}$ & 40 & 25 \\
\hline
\end{tabular}


Table 2. Reagent systems capable of fully dissolving DU. Treatment conditions for complete dissolution presented.

\begin{tabular}{|c|c|c|c|c|c|c|}
\hline $\begin{array}{l}\text { Reagent } \\
\text { system }\end{array}$ & $\begin{array}{l}\text { Conc. } \\
\text { Mol/L }\end{array}$ & $\begin{array}{l}\text { Time to } \\
\text { DU } \\
\text { dissoluti } \\
\text { on }\end{array}$ & $\begin{array}{l}\text { Initial } \\
\text { Temp } \\
\text { C }\end{array}$ & $\begin{array}{l}\text { Volume } \\
\text { per gram } \\
\text { DU }(\mathrm{mL})\end{array}$ & $\begin{array}{l}\mathrm{UO}_{2} \\
\text { solids } \\
\text { formed? }\end{array}$ & $\begin{array}{l}\text { Off gas } \\
\text { produced? }\end{array}$ \\
\hline $\begin{array}{l}\text { Sodium } \\
\text { hypochlorite }\end{array}$ & 1.0 & $\begin{array}{l}45 \\
\text { minutes }\end{array}$ & 60 & 25 & Yes & $\begin{array}{l}\text { Very small } \\
\text { amount }\end{array}$ \\
\hline $\begin{array}{l}\text { Sodium } \\
\text { hypochlorite } \\
\text { Hydrogen } \\
\text { peroxide }\end{array}$ & $\begin{array}{l}1.0 \\
5.0\end{array}$ & $\begin{array}{l}>24 \\
\text { hours }\end{array}$ & 25 & $\begin{array}{l}25 \\
5 \text { (added } \\
\text { dropwise) } \\
\end{array}$ & Yes & $\begin{array}{l}\text { Moderate } \\
\text { amounts of } \\
\text { colorless } \\
\text { offgas } \\
\end{array}$ \\
\hline $\begin{array}{l}\text { Sulfuric acid } \\
\text { Hydrochloric } \\
\text { acid } \\
\text { Hydrogen } \\
\text { peroxide }\end{array}$ & $\begin{array}{l}7.5 \\
0.2\end{array}$ & 6 hours & 65 & $\begin{array}{l}10 \text { (added } \\
\text { dropwise) } \\
\end{array}$ & No & $\begin{array}{l}\text { Vigorous } \\
\text { off-gasing } \\
\text { after each } \\
\mathrm{H}_{2} \mathrm{O}_{2} \\
\text { addition } \\
\end{array}$ \\
\hline $\begin{array}{l}\text { Sulfuric acid, } \\
\text { Nitric acid }\end{array}$ & $\begin{array}{l}7.5 \\
1.1 \\
\end{array}$ & $\begin{array}{l}20 \\
\text { minutes }\end{array}$ & 25 & 25 & No & No \\
\hline $\begin{array}{l}\text { Hydrochloric } \\
\text { acid } \\
\text { Ferric } \\
\text { chloride }\end{array}$ & 3.0 & 4 hour & 25 & 50 & Yes & No \\
\hline $\begin{array}{l}\text { Hydrochloric } \\
\text { acid } \\
\text { Ferric sulfate } \\
\text { Hydrogen } \\
\text { peroxide }\end{array}$ & $\begin{array}{l}3.0 \\
0.2 \\
10.0 \\
\end{array}$ & 4 hour & 25 & 50 & Yes & No \\
\hline $\begin{array}{l}\text { Phosphoric } \\
\text { acid } \\
\text { Hydrochloric } \\
\text { acid }\end{array}$ & 7.0 & $\begin{array}{l}12 \mathrm{~min} \\
\text { at }\end{array}$ & 25 & 10 & No & $\begin{array}{l}\text { Moderate } \\
\text { amounts of } \\
\text { colorless } \\
\text { offgas } \\
\end{array}$ \\
\hline $\begin{array}{l}\text { Sodium } \\
\text { hydroxide } \\
\text { Hydrogen } \\
\text { peroxide } \\
\end{array}$ & 1.0 & 1 hour & 40 & 50 & No & No \\
\hline $\begin{array}{l}\text { Nitric acid } \\
\text { Sulfuric acid }\end{array}$ & $\begin{array}{l}11.5 \\
2.0 \\
\end{array}$ & $20 \mathrm{~min}$ & 25 & 25 & No & No \\
\hline $\begin{array}{l}\text { Nitric acid } \\
\text { Phosphoric } \\
\text { acid }\end{array}$ & $\begin{array}{l}11.5 \\
0.3\end{array}$ & 2 hour & 40 & 25 & No & No \\
\hline $\begin{array}{l}\text { Nitric acid } \\
\text { Hydrochloric } \\
\text { acid }\end{array}$ & $\begin{array}{l}11.5 \\
0.3\end{array}$ & 3 hour & 40 & 25 & No & No \\
\hline
\end{tabular}


Figure 1: SEM photograph of the solid formed in the reaction of $1 \mathrm{~mol} / \mathrm{L}$ phosphoric acid, $3 \mathrm{~mol} / \mathrm{L}$ hydrochloric acid solution with uranium metal.

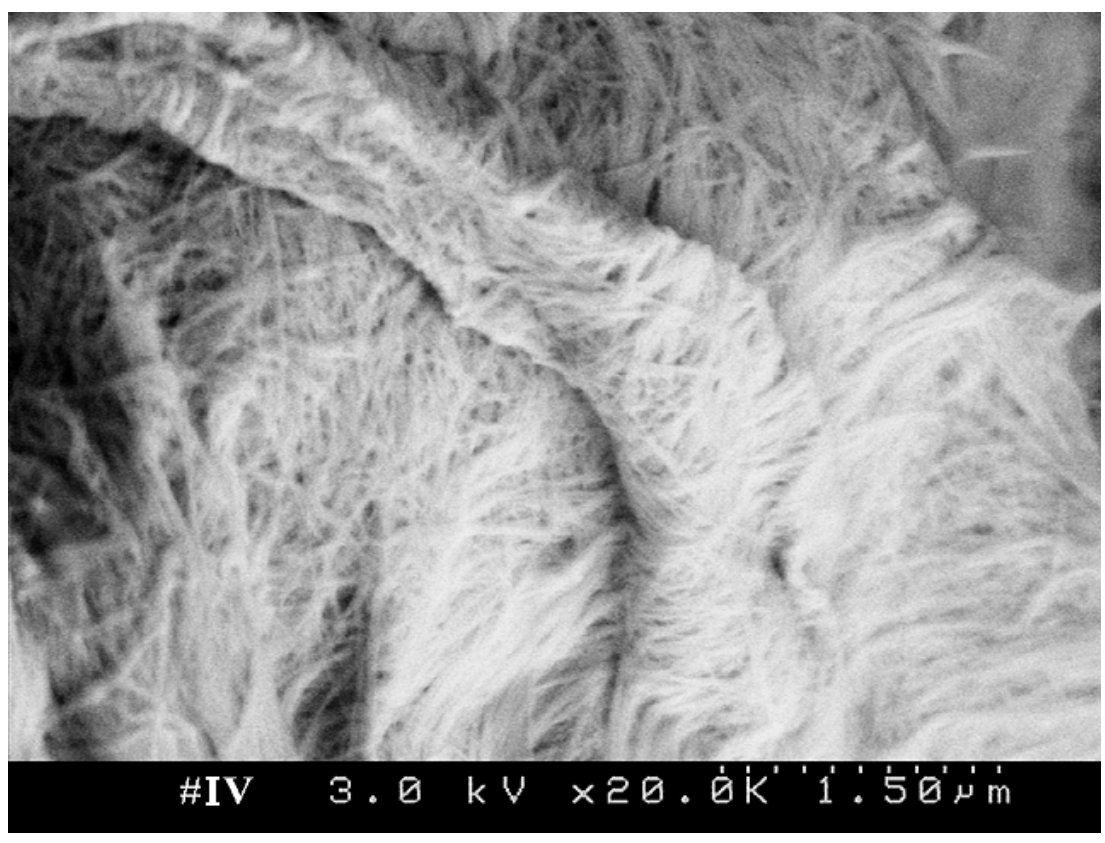


Figure 2: Schematic of full-scale DU treatment system at LLNL.

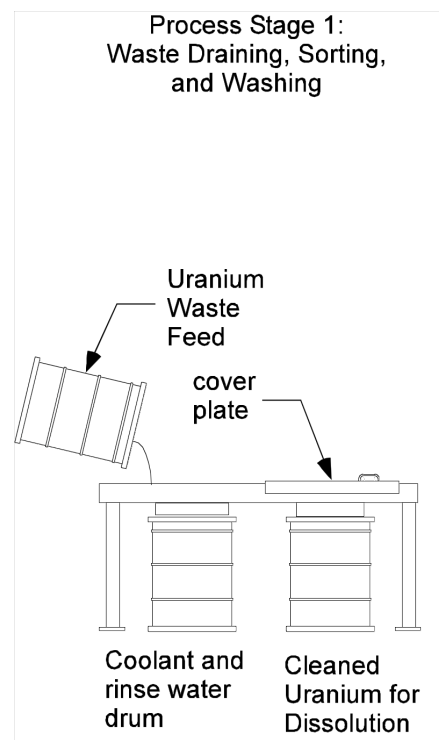

Process Stage 2:

DU Dissolution

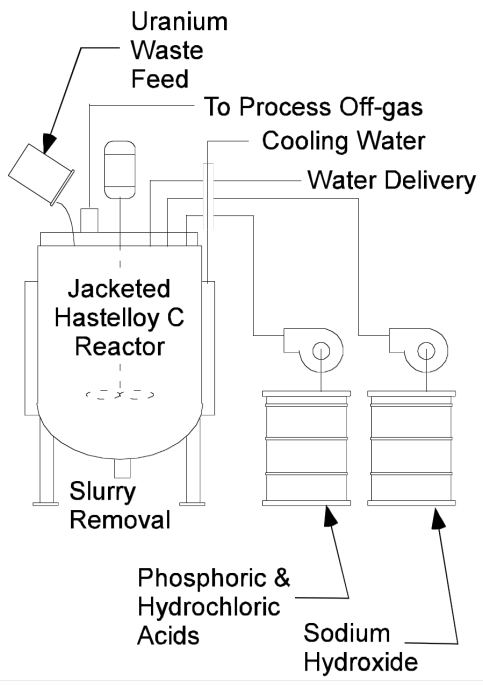

Process Stage 3:

Solidification of Dissolution

Residuals

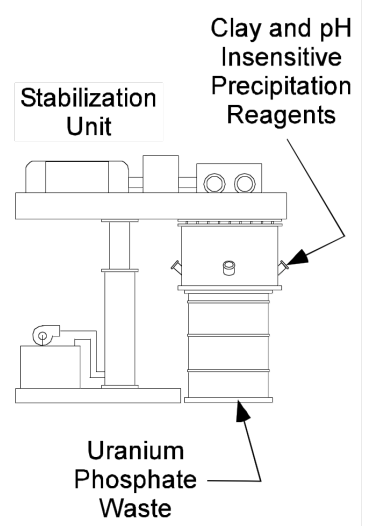

